\title{
ANTARCTIC ATMOSPHERE RESPONSE TO SUN-EARTH INTERACTIONS
}

\section{Emília Correia*1, Maria Thereza Quevedo ${ }^{1}$, Amanda Junqueira Paz ${ }^{2}$, Alexandre Rodel de Almeida ${ }^{2}$}

'Instituto Nacional de Pesquisas Espaciais, CEP: 12227-010, São José dos Campos, Brazil

2Centro de Rádio Astronomia e Astrofísica Mackenzie, Escola de Engenharia, Universidade Presbiteriana Mackenzie, Rua da Consolação 930, Ed. Modesto Carvalhosa $7^{\circ}$ andar. CEP: 01302-907. São Paulo, SP, Brazil.

*e-mail: ecorreia@craam.mackenzie.br

https://doi.org/10.4322/apa.2016.001

\begin{abstract}
The present study presents the ionosphere behavior obtained from radio sounding measurements conducted at "Comandante Ferraz" Brazilian Antarctic Station. The results are discussed in the light of the long-trend behavior obtained in association with 11-year solar cycle. The long-term ionosphere behavior is controlled by the ultraviolet solar radiation, presenting variations closely associated with the solar cycle. In contrast, it is strongly affected by the excess of X-ray emission produced during the solar flares. Studies have also shown that the ionosphere is strongly disturbed during local wintertime due to the effect of atmospheric waves originated in the troposphere/stratosphere in their upward propagation. Recent studies on the ionosphere have improved our understanding of its response to natural phenomena, and about its coupling with lower atmospheric layers. The energy exchange among atmospheric layers might be an important driver in the climate conditions/changes, which affect the terrestrial and marine environment, especially in the polar region.
\end{abstract}

Keywords: Atmosphere; Sun-Earth Interaction; Atmospheric Radio Sounding

\section{Introduction}

The low ionosphere is formed/maintained by the solar Lyman-alpha $(121.5 \mathrm{~nm})$ ionizing radiation during quiet conditions (Nicolet \& Aikin, 1960). This radiation presents variability in close association with the 11-year solar cycle, which affects the ionization processes (Lastovicka, 2006). This effect has been obtained from long-term measurements of very low radio frequency (VLF) signals propagating over long distances inside the Earth-ionosphere waveguide during the $22^{\text {nd }}, 23^{\text {rd }}$ and $24^{\text {th }}$ solar cycles (Thomson \& Clilverd, 2000; Correia et al., 2011 and 2013a, respectively). In addition, the excess X-ray radiation produced during solar flares also affects the ionosphere in time scale of minutes to hours.

The solar activity influence on the low ionosphere has also been evaluated from the VLF sudden phase anomalies (SPA) resulting from the excess of X-ray emission produced during solar flares. The X-ray events capable of producing significant SPAs must present intensities higher than $3.0 \times 10^{-7} \mathrm{~W} / \mathrm{m}^{2}$ and $4.2 \times 10^{-7} \mathrm{~W} / \mathrm{m}^{2}$, respectively, in the minimum and maximum phases of solar activity (Raulin et al., 2010). In addition to solar activity, the ionosphere is also affected by space weather conditions, which involve various inter-related phenomena, with geomagnetic storms (eg. Buonsanto, 1999), solar proton events (SPEs), and relativistic electron precipitation (REP) events considered the most important. Nevertheless, there are other phenomena such as changes in the cosmic ray flux and interplanetary magnetic field, which are less important or included in geomagnetic activity variations.

The ionosphere is not only affected by phenomena from geospace, it is also strongly influenced during the local wintertime by upward propagating atmospheric waves, particularly the gravity and planetary waves originated in the neutral atmosphere (Lastovicka, 2006). The effects of planetary waves were detected in the VLF measurements conducted at "Comandante Ferraz" Brazilian Antarctic Station (EACF) from 2004 to 2011 (Correia et al., 2011; 2013a). The atmospheric waves play an important role in the transport of energy and momentum from the lower to the upper atmosphere layers, affecting the thermal structure 
and general circulation in the middle and upper atmosphere (Takahashi et al., 1999, Bageston et al., 2011). The year-toyear variation in ozone holes are also affected by differences in atmospheric temperature and circulation (e.g. Newman et al., 2008).

In this study, we present the ionosphere behavior obtained from soundings performed with distinct radio techniques (VLF, GPS and ionosonde) from 2010 to 2014, which are compared with the long-term trend between 2007 and 2013. The ionosphere behavior is also evaluated during a geomagnetic storm occurred on 26 September 2011.

\section{Materials and Methods}

The ionosphere behavior is obtained using different radio sounding techniques:

VLF measurements are performed within the $1-50 \mathrm{kHz}$ frequency range with $20 \mathrm{~ms}$ time resolution using an Atmospheric Weather Electromagnetic system for Observation, Modeling and Education system (AWESOME, Scherrer et al., 2008) operating at EACF $\left(62.11^{\circ} \mathrm{S}, 58.41^{\circ} \mathrm{W}\right.$, since 2007) and Itapetinga Radio Observatory in Atibaia, Sao Paulo state (ROI $-23.21^{\circ} \mathrm{S}, 46.51^{\circ} \mathrm{W}$, since 2006). The VLF technique is used to study the lower part of the ionosphere, the D-region located between 60 and $85 \mathrm{~km}$ of height. The American Navy Cutler VLF transmitter (NAA $-44.67^{\circ} \mathrm{N}, 64.27^{\circ} \mathrm{W}$ ) was used in this study. To evaluate the solar influence on the ionosphere, we compared the daytime maximum VLF amplitude from NAA received in Atibaia, Sao Paulo state, with the solar Lyman-alpha radiation and daily sunspot number ( $\mathrm{Rz}$, http://sidc.oma.be/sunspotdata/). We considered only the Atibaia data because of the lack of measurements in 2012 at EACF. The daytime VLF amplitude is measured at $~ 15: 00 \mathrm{UT}$ (local noon time) using an AWESOME system operating at ROI.

The Total Electron Content (TEC) of the ionosphere is obtained using dual-frequency GPS receivers. The phase shifts produced by the dispersive nature of the plasma are directly proportional to TEC, which is the integral line of the electron concentration along the path between satellite and receiver. The ionosphere has been monitored at EACF since 2004 using a Javad GPS receiver with best time resolution of $1 \mathrm{~s}$. VTEC is the vertical TEC estimated from Rinex data using the first step of the Implementation of La Plata Ionospheric Model (LPIM) applicative developed in the National La Plata University, Argentina (Brunini et al., 2008). The seasonal mean diurnal variation of the ionosphere behavior was obtained considering the monthly averages of the 1-h VTEC for each day in January, March, June, and September as representative of the summer solstice, autumn equinox, winter solstice, and spring equinox in the southern hemisphere, respectively.

The ionosphere at EACF has also been monitored using a Canadian Digital Ionosonde (CADI, MacDougall, 1997) since 2009. The CADI consists of one transmitter, at frequencies between 1 and $20 \mathrm{MHz}$, and four receivers to detect the reflected signals. The echoes of the signal reflected by the $\mathrm{F}$ and $\mathrm{E}$ regions of the ionosphere provide a profile of reflection frequency versus virtual height (ionogram), which provides information on the electron density (directly related to the reflection frequency) profile as a function of actual height (Piggott \& Rawer, 1972). The CADI is programmed to obtain ionograms every $5 \mathrm{~min}$ and drift measurements every $2.5 \mathrm{~min}$. The scaling of ionograms is obtained using a software developed at Universidade do Vale do Paraíba (UNIVAP) called UNIVAP Digital Ionosonde Data Analysis (UDIDA, Fagundes et al., 2005). This study analyzes the $\mathrm{F}$ region conditions of the ionosphere obtained from ionograms that provide foF 2 parameter, which is the F2 layer critical frequency and shows information on the ionosphere electron density at $\sim 250 \mathrm{~km}$ height, as well as the h'F2 parameter, which shows the virtual height of this layer.

The geomagnetic index Dst was obtained from the World Data Center for Geomagnetism of Kyoto (http://wdc.kugi. kyoto-u.ac.jp/wdc/Sec3.html).

The stratosphere temperature was measured over EACF by SABER experiment onboard TIMED satellite (http://saber. gats-inc.com), when it was crossing a region of approximately $10 \times 10$ degrees at $60-70 \mathrm{~km}$ of height over the EACF.

\section{Results}

\section{Solar forcing of the ionosphere}

The maximum phase of the $24^{\text {th }}$ solar cycle that started in the beginning of 2010 occurred during 2013-2014, as shown by the solar cycle sunspot progression presented in Figure 1a (http://www.swpc.noaa.gov/SolarCycle/, access: 7 July 2014), as well by the Ly-alpha solar radiation (Figure 1b). 

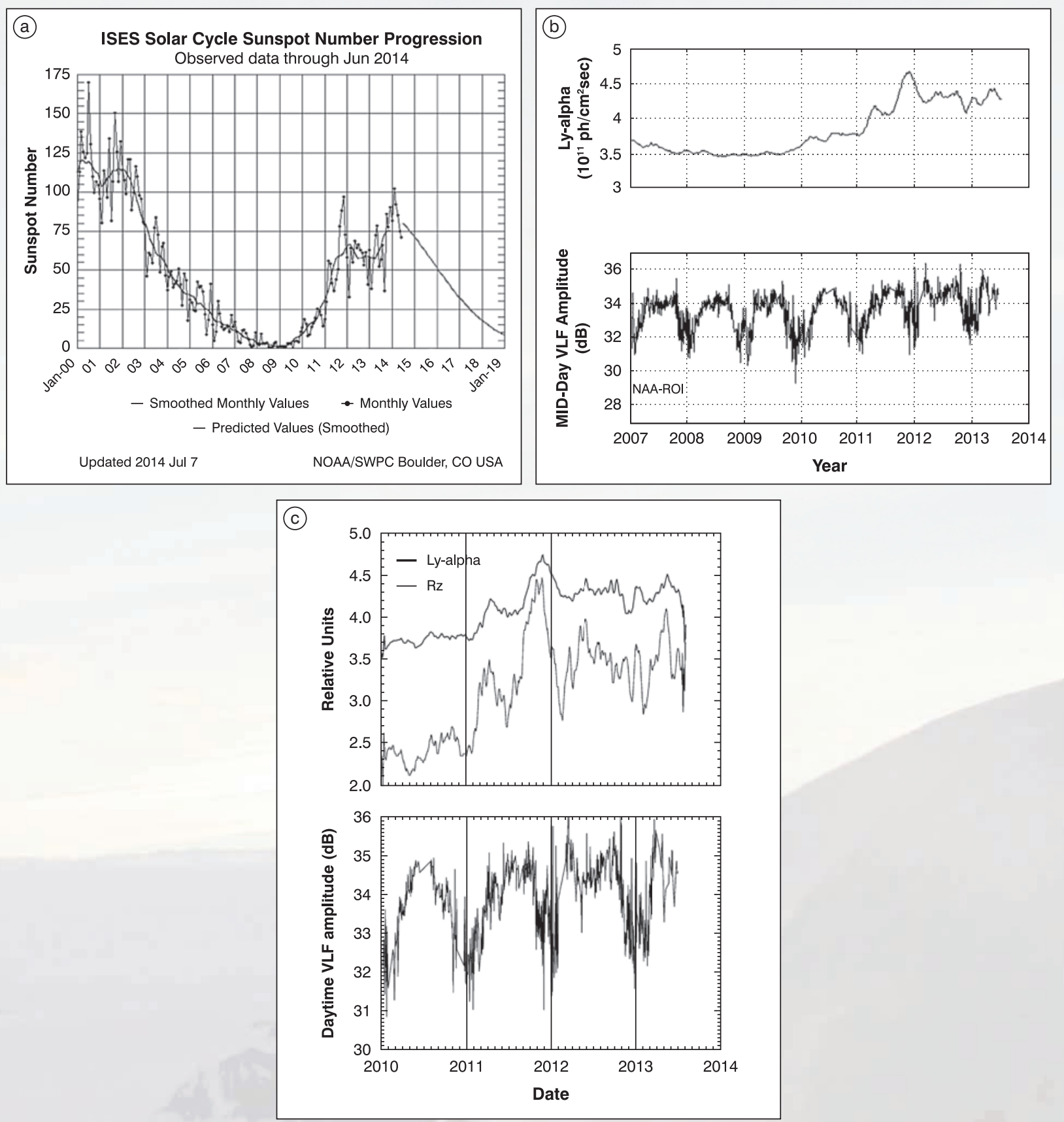

Figure 1. Sunspot Number Progression with the observations for the $23^{\text {rd }}$ and progression for the $24^{\text {th }}$ solar cycles (a). Daytime VLF amplitude obtained at 15:00UT (local noon time) compared with the 31-day smoothly daily sunspot number and Lyman-alpha radiation from 2007 to 2013 (b). Daytime VLF amplitude compared with Lyman-alpha and Sunspot Number (Rz) from 2010 to 2013 (c).

The analysis of daytime VLF amplitude from 2007 to 2013 shows an increase tendency accompanying the solar radiation (Figure $1 \mathrm{~b}$ ). This association is evident around July, when the ionosphere behavior at NAA-ROI VLF path is more stable. This result means that the electron density at the low ionosphere changed in close association with solar activity, which stayed almost stable from 2007 to 2009 during the minimum phase of $23^{\text {rd }}$ solar cycle and increased from 2010 to 2012 during the rise phase of the $24^{\text {th }}$ cycle, stabilizing after 2013 when solar activity reached 
the highest level. Figure 1c shows, in detail, the VLF amplitude after 2010, which is compared with Ly-alpha solar radiation and the daily sunspot number (Rz, http:// sidc.oma.be/sunspot-data/), showing good correlation with both.
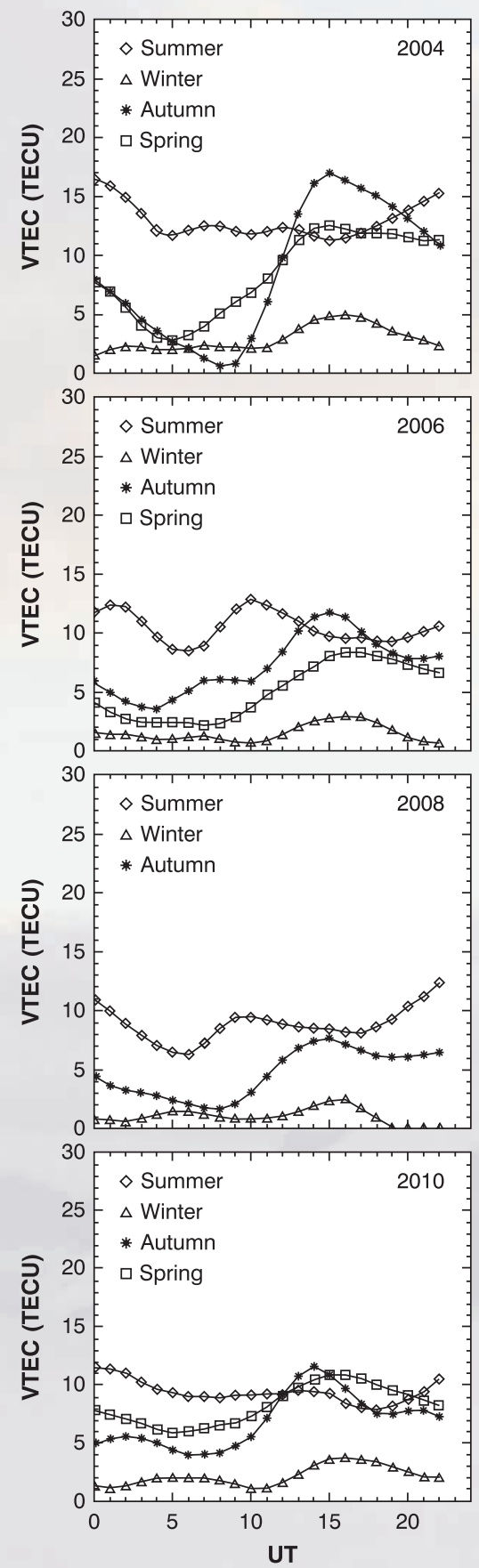

\section{Ionosphere seasonal behavior - GPS measurements}

The mean diurnal variation of VTEC at EACF for each season from 2004 to 2011 shows a clear peak between 13:00 UT and 17:00 UT (LT = UT - 4) (Figure 2), but
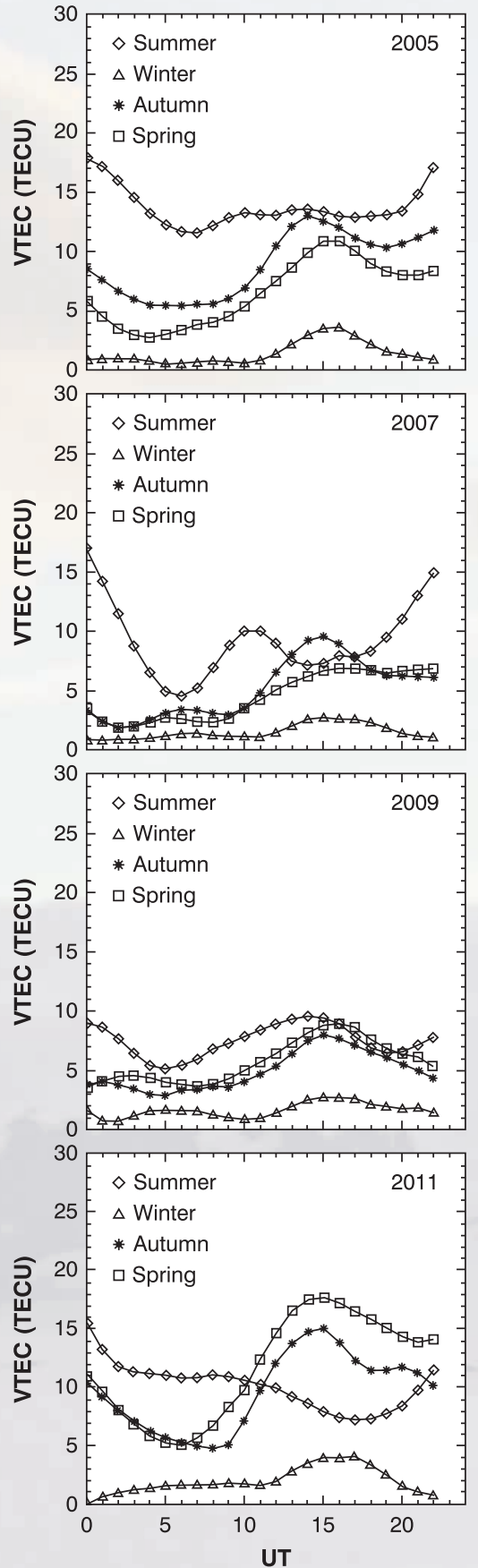

Figure 2. Seasonal variability of the VTEC for each year from 2004 to 2011 . Each curve refers to the mean diurnal variation that is representative of each season, as observed at EACF $\left(\sim 62^{\circ} \mathrm{S}\right)$. (Adapted from Correia et al., 2013b). 
in January (summer), when is daytime almost 24 hours, therefore the ionosphere condition is almost stable all day. The results also show the presence of a semi-annual anomaly, with higher values of daytime VTEC during the equinoxes (spring and autumn).

\section{Space weather forcing of the ionosphere}

The space weather forcing is presented here considering the ionosphere response to the geomagnetic storm that occurred on September 26, 2011. This geomagnetic storm presents a peak of -120 nT in the Dst index, which means a moderately strong storm. The ionosphere shows a positive storm that was observed at EACF as enhancements in foF2 parameter and VTEC from 1200 to 2300 UT, which is during the main phase of geomagnetic storm (Figure 3). The VTEC increased approximately 50 TECU ( 1 TECU $=10^{16}$ electrons $/ \mathrm{m}^{2}$ ), which is approximately 4 times the quiet day level. The foF2 parameter increased from 6 to $12 \mathrm{MHz}$, which means a density enhancement of $\sim 5 \times 10^{32}$ electrons $/ \mathrm{m}^{3}$, also approximately 4 times the quiet level condition.

\section{Atmospheric forcing of the ionosphere}

Daytime VLF amplitude shows high fluctuations from October to March in NAA-ROI VLF path (Figures $1 \mathrm{~b}$ and 1c). Considering that this VLF path occurs mostly in the
Northern Hemisphere, the fluctuations are dominated by the atmospheric conditions during the winter season in that hemisphere. In order to characterize these fluctuations, a wavelet analysis was applied to VLF amplitude data for 2007, which is compared with stratosphere temperature at $70 \mathrm{~km}$ measured by SABER over EACF. The wavelet analysis shows the fluctuations occur preferentially with the periods of 12-20 days, 8-10 days, and $~ 5$ days, which are typical of planetary waves (Figure 4 ). The analysis also shows that the most significant component presents $\sim 16$-day period, which is present in the VLF amplitude, as well as in the stratosphere temperature over EACF.

\section{Discussion}

The Sun is the main source of energy on Earth. It is responsible for the Earth's environmental conditions and life. In contrast, the atmosphere is also an important element because it filters part of the solar radiation that is harmful to terrestrial and marine life, especially in X-rays and ultraviolet spectral range. Solar radiation is not constant and presents variations in different time scales, mainly associated with the Gleissberg cycle ( $~ 90$ years), Hale cycle ( 22 years) and Schwabe cycle ( $\sim 11$ years), as well as with 27 -day time scale associated with the solar rotation.
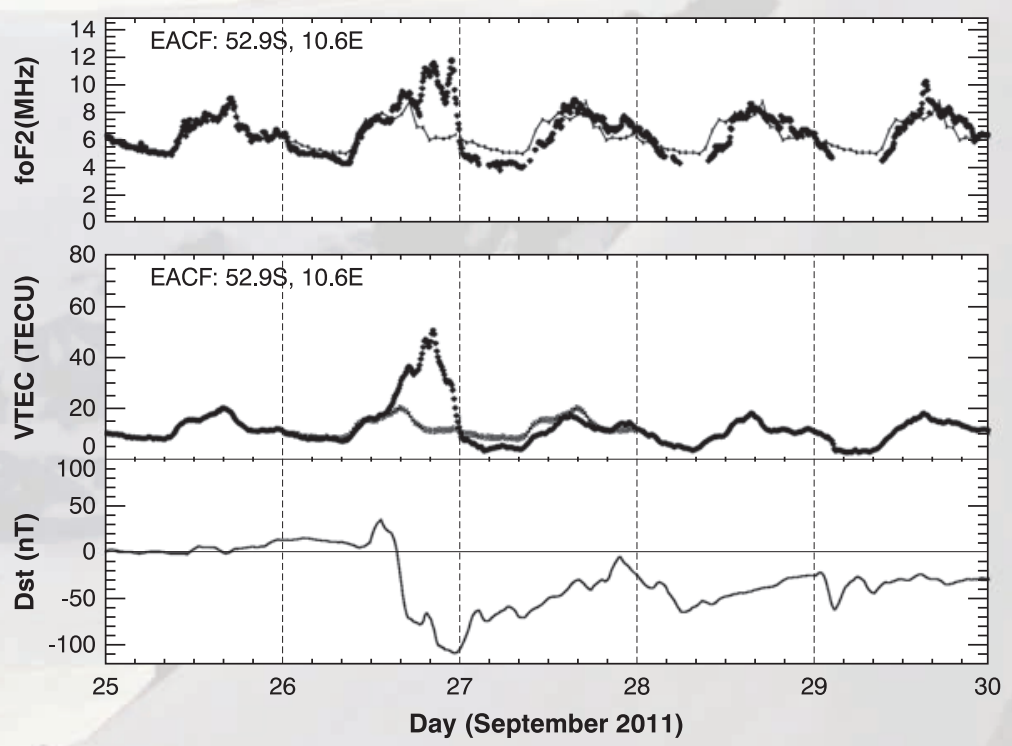

Figure 3. VTEC and foF2 variation measured at EACF during the geomagnetic storm of September 26, 2011. The thicker lines in VTEC and foF2 refer to the disturbed day. 
(a)

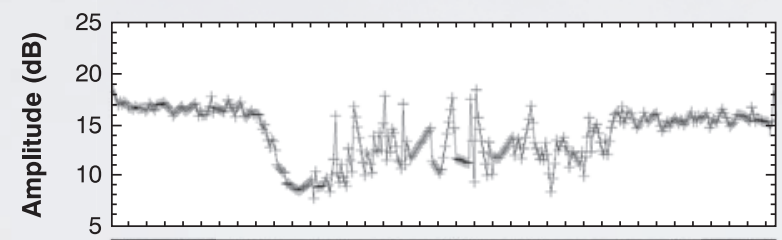

PSD $\left[\mathrm{dB}^{2}\right]$
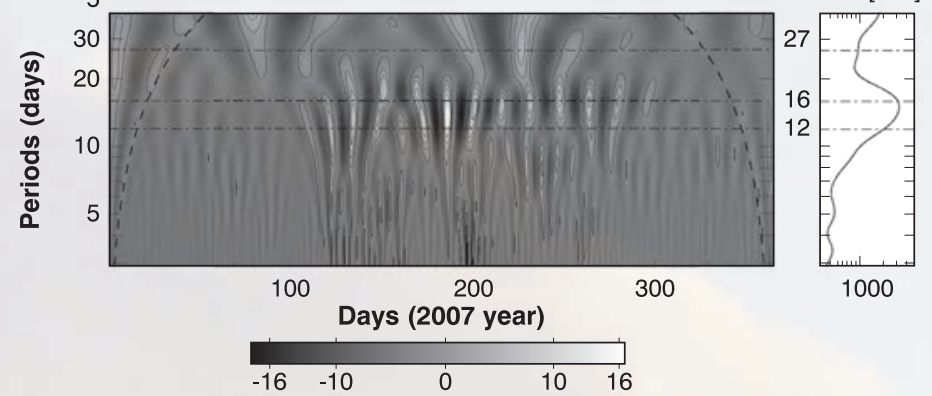

1000

(b)

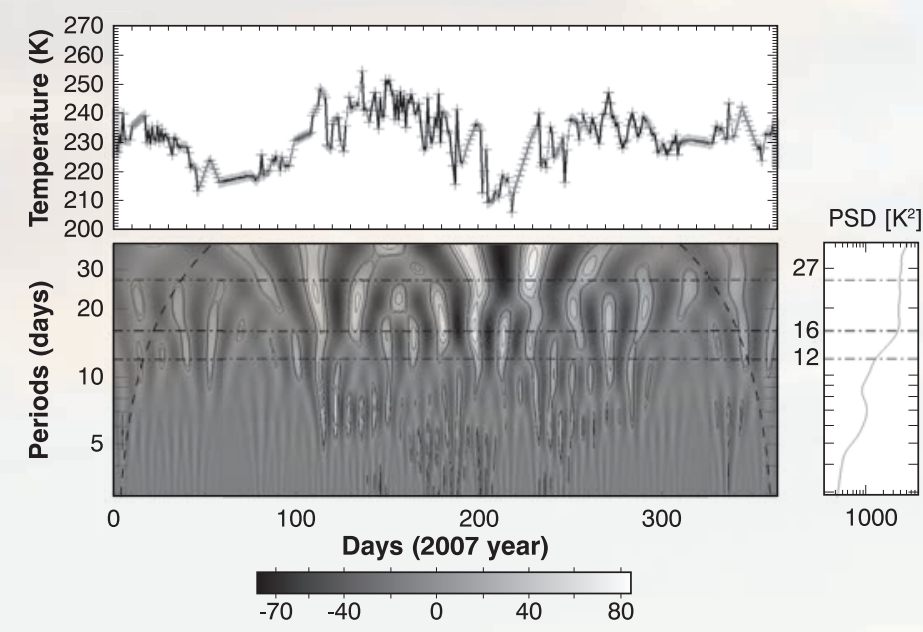

Figure 4. Wavelet analysis of the mid-day VLF amplitude measured at EACF (a) and of the stratosphere temperature (b) for 2007 . The stratosphere temperature used here was measured with SABER experiment over EACF at $\sim 70 \mathrm{~km}$ of height during daytime. (Adapted from Correia et al., 2011).

A long-term daytime VLF amplitude study shows 11-year modulation in close association with the solar Lyman-alpha variation, as observed from 2007 to 2014 , during the $23^{\text {rd }}$ and $24^{\text {th }}$ solar cycles, which is in agreement with previous works that had shown this association during the last three solar cycles (Thomson \& Clilverd, 2000; Correia et al., 2011, 2013a). This good association was also obtained using VTEC long-term data (2004-2011) from measurements performed at EACF, which also shows a good association with ionosphere behavior at $\sim 300 \mathrm{~km}$ with 11-year ultraviolet solar variation (Correia et al., 2013b).

VTEC data at EACF show a seasonal mean diurnal variation, presenting a maximum near 14:00 LT in the equinoxes and winter seasons, but not in summer, that shows an almost flat variation due to the long day. These data also show the presence of the semi-annual anomaly, with higher VTEC values during the equinoxes (spring and autumn seasons) than in summer. This result obtained at EACF, which is at mid-latitude, is similar to what has been observed at all latitudes (e.g. Kumar et al., 2012; Chung et al., 2011).

The daytime VLF amplitude has also shown large day-today variations occurring preferentially during wintertime, which suggests that the low ionosphere is strongly affected by 'meteorological processes'. This idea is reinforced by the fact that they appeared in close association with temperature variations in the stratosphere (Correia et al., 2011), and the wavelet analysis showed that the most significant component with $\sim 16$-day period is present at both. This 
16-day component has been reported as a typical planetary wave of stratospheric/tropospheric origin (ex. Forbes et al., 1995; Espy et al., 1997; Mitchell et al., 1999; Luo et al., 2002; Jiang et al., 2005; Day \& Mitchell, 2010). These results show that the lower ionosphere is strongly affected by the dynamics of the lower-lying atmospheric layers. This effect occurs predominantly during wintertime, suggesting a vertical coupling, which can be attributed to the upward propagation of planetary waves favored by westerly winds (Correia et al., 2011, 2013a).

\section{Conclusion}

This study shows that the Earth's atmosphere, particularly the ionosphere, is controlled by Sun-Earth interaction, but also by lower-lying atmosphere dynamics, especially during local winter season.

The long-term conditions of the ionosphere are strongly controlled by the solar Ly-alpha radiation from above, but are also affected by neutral atmospheric waves from below, which change its chemistry and physics. During geomagnetic disturbed periods, the ionosphere is also affected by injection of particles in the magnetosphere, which strongly impacts the ionosphere, especially at higher latitudes, where part of them could precipitate, increasing the electron density and changing the electrical currents, generating large scale winds.
The simultaneous monitoring of the different atmospheric layers is important for understanding how the solar energy input is transported to lower layers and for establishing the connection between solar energy input and climate changes. The knowledge of energy balance in the ionosphere and its behavior at different time scales, varying from years to months, is important because it affects the environmental conditions and, consequently, terrestrial and marine life.

\section{Acknowledgments}

This work was partially sponsored by the Brazilian Antarctic Program/Ministry of the Environment (PROANTAR/ MMA, Portuguese acronym), National Council for Scientific and Technological Development (CNPq, process no.: 52.0186/06-0 and 556872/2009-6), Interministerial Commission for Resources of the Sea (SECIRM, Portuguese acronym), National Institute for Space Research (INPE, Portuguese acronym), and INCT-APA (Instituto Nacional de Ciência e Tecnologia Antártico de Pesquisas Ambientais, CNPq process $n^{\circ} 574018 / 2008-5$ and FAPERJ process $n^{\circ}$ E-16/170.023/2008). The authors would like to thank the technicians Armando Hadano and José Roberto Chagas from INPE for their support in Antarctica. AJP holds a grant by $\mathrm{CNPq}$ (process no.: 163576/2012-2). The authors are grateful to SABER science and data processing teams for their extensive efforts to produce a high quality data set.

\section{References}

Bageston, J. V., Wrasse, C. M., Hibbins, R. E., Batista, P. P., Gobbi, D., Tahakashi, H., Fritts, D. C., Andrioli, V. F., Fechine, J., \& Denardini, C. M. (2011). Case study of a mesospheric wall event over Ferraz Station, Antarctica (62 S). Annales Geophysicae, 29(1), 209-219.

Brunini, C., Meza, A., Gende, M., \& Azpilicueta, F. (2008). South American regional ionospheric maps computed by GESA: A pilot service in the framework of SIRGAS. Advances in Space Research, 42(4), 737-744.

Buonsanto, M. J. (1999). Ionospheric storms: a review. Space Science Reviews, 88(3-4), 563-601.

Chung, J. K., Jee, G., \& Lee, C. N. (2011). Global positioning system total electron content variation over King Sejong Station in Antarctica under the solar minimum condition between 2005 and 2009. Journal of Astronomy and Space Sciences, 28(4), 305-310.

Correia, E., Kaufmann, P., Raulin, J.-P., Bertoni, F. C., \& Gavilán, H. R. (2011). Analysis of daytime ionosphere behavior between 2004 and 2008 in Antarctica. Journal of Atmospheric and Solar-Terrestrial Physics, 73(16), 2272-2278.

Correia, E., Raulin, J.-P., Kaufmann, P., Bertoni, F., \& Quevedo, M. T. (2013a). Inter-hemispheric analysis of daytime low ionosphere behavior from 2007 to 2011. Journal of Atmospheric and Solar-Terrestrial Physics, 92, 51-58.

Correia, E., Paz, A.J. \& Gende, M.A. (2013b). Characterization of GPS-TEC in Antarctica from 2004 to 2011. Annals of Geophysics, 56: R0217-1-R0217-5. 
Day, K. A., \& Mitchell, N. J. (2010). The 16-day wave in the Arctic and Antarctic mesosphere and lower thermosphere. Atmospheric Chemistry and Physics, 10(3), 1461-1472.

Espy, P. J., Stegman, J., \& Witt, G. (1997). Interannual variations of the quasi-16-day oscillation in the polar summer mesospheric temperature. Journal of Geophysical Research, 102(D2), 1983-1990.

Fagundes, P.R., Pillat, V.G., Bolzan, M. J.A., Sahai, Y., Becker- Guedes, F., Abalde, J.R., Aranha S.L., \& Bittencourt, J.A. (2005). Observations of F-layer electron density profiles modulated by pw type oscillations in the equatorial ionospheric anomaly region. Journal of Geophysical Research, 110(A12302), 1-8.

Forbes, J. M., Hagan, M. E., Miyahara, S., Vial, F., Mason, A. H., Meek, C. E., \& Portnyagin, Y. I. (1995). Quasi 16-day oscillation in the mesosphere and lower thermosphere. Journal of Geophysical Research, 100(D5), 9149-9163.

Jiang, G. Y., Xiong, J. G., Wan, W. X., Ning, B. Q., Liu, L. B., Vincent, R. A., \& Reid, I. (2005). The 16-day waves in the mesosphere and lower thermosphere over Wuhan (30.61N, 114.51E) and Adelaide (351S, 1381E). Advances in Space Research, 35(11), 2005-2010.

Kumar, S., Priyadarshi, S., Krishna, S. G., \& Singh, A. K. (2012). GPS-TEC variations during low solar activity period (20072009) at Indian low latitude stations, Astrophyical. Space Science, 339(1), 165-178.

Lastovicka, J. (2006). Forcing of the ionosphere by waves from below. Journal of Atmospheric and Solar-Terrestrial Physics, 68(3-5), 479-497.

Luo, Y., Manson, A. H., Meek, C. E., Meyer, C. K., Burrage, M. D., Fritts, D. C., Hall, C. M., Hoching, W. K., MacDougall, J., Riggin, D. M., \& Vincent, R. A. (2002). The 16-day planetary waves: multi-MF radar observations from the arctic to equator and comparisons with the HRDI measurements and the GSWM modeling results. Annales Geophysicae, 20(5), 691-709.

MacDougall, J. W. (1997). Canadian advanced digital ionosonde users manual. University of Western Ontario, Scientific Instrumentation. $90 \mathrm{p}$.

Mitchell, N. J., Middleton, H. R., Beard, A. G., Williams, P. J. S., \& Muller, H. G. (1999). The 16-day planetary wave in the mesosphere and lower thermosphere. Annales Geophysicae, 17(11), 1447-1456.

Newman, P. A., Herman, R., Bevilacqua, R., Stolarski, R., \& Keating, T.(2008). Ozone and UV Observations. In A. R. Ravishankara, M. J. Kurylo \& C. A. Ennis (Eds.), Trends in Emissions of Ozone-Depleting Substances, Ozone Layer Recovery, and Implications for Ultraviolet Radiation Exposure: report by the US Climate Change Science Program and Subcommittee on Global Change Research (pp. 79-110). Asheville: Department of Commerce, NOAA's Layer Recovery, and Implications for Ultraviolet Radiation Exposure National Climatic Data Center.

Nicolet, M., \& Aikin, A. C. (1960). The Formation of the D-Region of the lonosphere. Journal of Geophysical Research, 65(5), 1469-1483

Piggott, W. R., \& Rawer, K. (1972). U.R.S.I. handbook of ionogram interpretation and reduction. Boulder: World Data Center A for Solar-Terrestrial Physics, NOAA. $90 \mathrm{p}$.

Raulin, J.-P., Bertoni, F. C. P., Gavila'n, H. R., Guevara-Day, W., Rodriguez, R., Fernandez, G., Correia, E., Kaufmann, K., Pacini, A., Stekel, T. R. C., Lima, W. L. C., Schuch, N. J., Fagundes, P. R., \& Hadano, R. (2010). Solar flare detection sensitivity using the South America VLF network (SAVNET). Journal of Geophysical Research, 115(A7), A07301. http:// dx.doi.org/10.1029/2009JA015154.

Scherrer, D., Cohen, M., Hoeksema, T., Inan, U., Mitchell, R., \& Scherrer, P. (2008). Distributing space weather monitoring instruments and educational materials worldwide for IHY 2007: the AWESOME and SID project. Advances in Space Research, 42(11), 1777-1785.

Takahashi, H., Batista, P. P., Buriti, R. A., Gobbi, D., Tsuda, N. T., \& Fukao, S. (1999). Response of the airglow OH emission, temperature and mesopause wind to the atmospheric wave propagation over Singaraki, Japan. Earth, Planets, and Space, $51(7-8), 863-875$.

Thompson, N. R., \& Clilverd, M. A. (2000). Solar cycle changes in daytime VLF subionospheric attenuation. Journal of Atmospheric and Solar-Terrestrial Physics, 62(7), 601-608. 


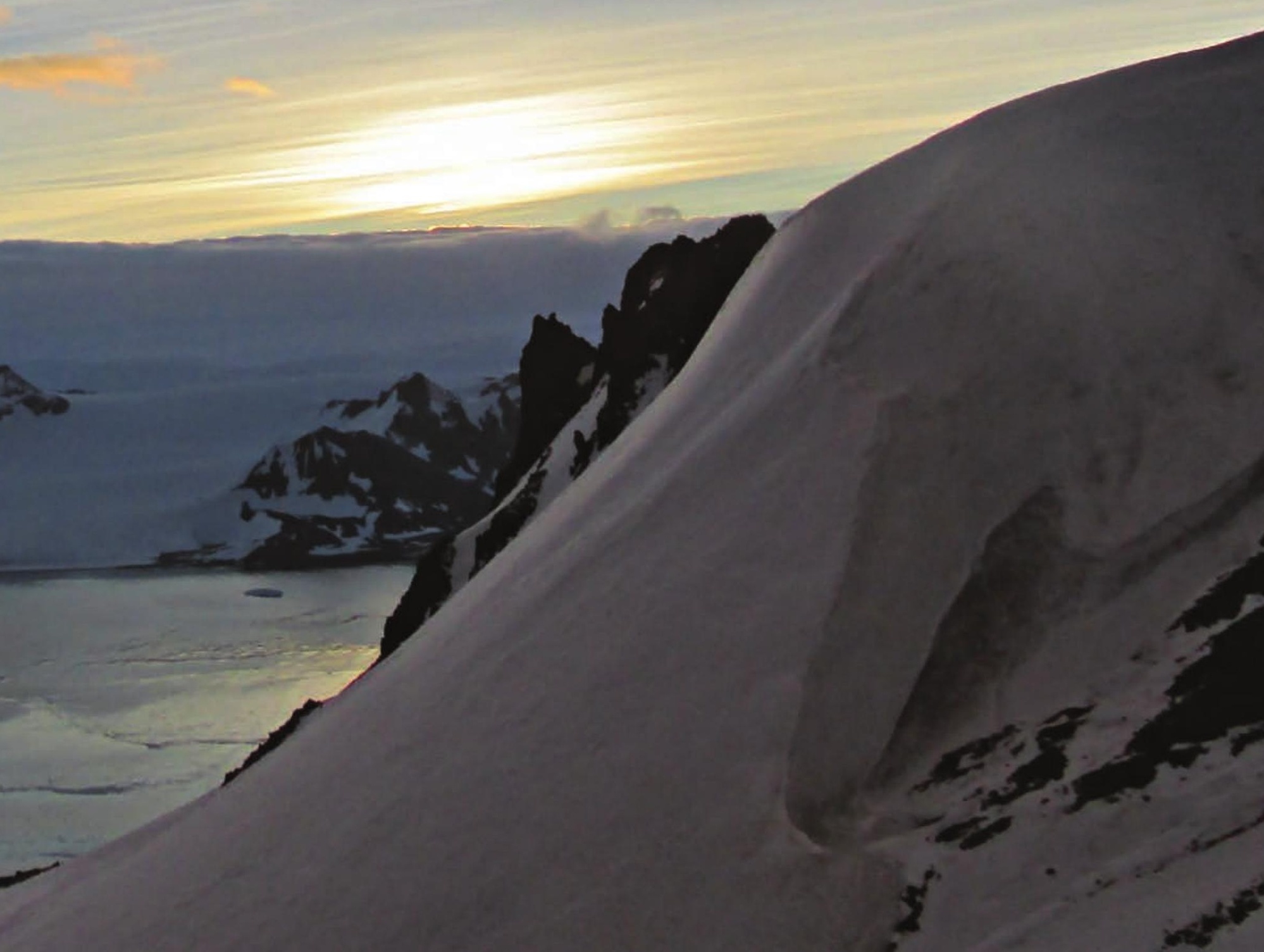


THEMATIC AREA 2

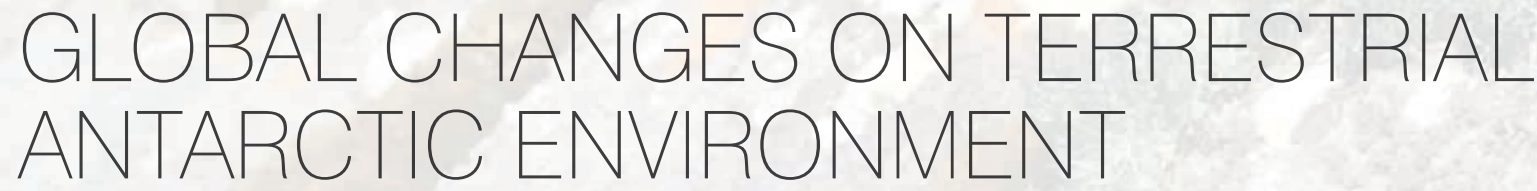

25 Trevizani, T. H., Silva, C. R. A., Majer, A. P., Ribeiro, A. P., Ferreira, P. A. L., Montone, R. C., \& Figueira, R. C. L. Arsenic and Heavy Metals in Soils from "Comandante Ferraz" Antarctic Station (King George Island) after Fire

30 Benemann, V. R. F., Petersen, E. S., Krüger, L., \& Petry, M. V. Influence of Sea Surface Temperature on Pelagic Seabird Distribution in the South Atlantic Ocean

34 Finger, J. V. G., Benemann, V. R. F., Petersen, E. S., Valls, F. C. L., \& Petry, M. V. Preliminary Information on the Diet of the Imperial Shag Phalacrocorax atriceps Breeding on Elephant Island, Antarctica

38 Petry, M. V., Werle, G. B., \& Aver, G. Breeding Distribution of Bird Species in Hannah Point Livingston Island, Archipelago of South Shetlands, Antarctica

42 Petry, M. V., Santos, C. R., Werle, G. B., \& Gustavo Aver. Distribution and Floating Population of Birds on Penguin Island, South Shetlands, Antarctica

46 Petry, M. V., Basler, A. B., Petersen, E. S., Aver, G. F., Krüger, L., Valls, F. C. L., \& Liana Chesini Rossi. Distribution of Seabird Colonies in Stinker Point, Elephant Island

50 Krüger, L., Petersen, E. S., \& Petry, M. V. Where do They Go? Year-Round Movements Reveal a Shift in the Distribution of Southern Giant Petrels During Winter

54 Vier, G. V., Finger, J. V. G., \& Petry, M. V. Distribution and Abundance of Antarctic and Subantarctic Seabirds within an Offshore Transect Between Rio Grande/RS and Rio de Janeiro/RJ 